\title{
The Unequal Impact of Food Insecurity on Cognitive and Behavioral Outcomes Among 5-Year-Old Urban Children
}

\author{
Savannah Hobbs, $\mathrm{MEd}^{1}$; Christian King, $\mathrm{PhD}^{2}$
}

\begin{abstract}
Objective: To examine the associations of food insecurity with children's cognitive and behavioral outcomes using quantile regression.

Design: Secondary analysis of the Fragile Families and Child Wellbeing Study dataset.

Participants: A total of 2,046 children aged 5 years.

Main Outcome Measures: Child behavioral outcomes were measured using externalizing (aggressive) and internalizing (emotional) behavior problems. Child cognitive outcomes were measured using the Peabody Vocabulary test and the Woodcock-Johnson letter-word identification test. Food insecurity was measured using the US Department of Agriculture's Food Security Module.
\end{abstract}

Analysis: Unconditional quantile regressions were employed. Statistical significance was set at $P \leq .05$.

Results: Negative associations between food insecurity and child behavior problems (externalizing and internalizing) were largest for children with the most behavior problems. For Peabody Vocabulary scores, the negative association with food insecurity was statistically significant only for children in the top half of the distribution $(\geq 50$ th percentile). The analysis found mixed evidence of an association between food insecurity and the Woodcock-Johnson letter-word identification test. These associations were similar for boys and girls.

Conclusions and Implications: Because children's cognitive skills and behavioral problems have longlasting implications and effects later in life, reducing the risk of food insecurity might particularly benefit children with greater externalizing and internalizing behavior problems.

Key Words: child behavior problems, child cognitive outcomes, food insecurity, quantile regression $(J$ Nutr Educ Behav. 2018;50:687-694.)

Accepted April 9, 2018. Published online May 9, 2018.

\section{INTRODUCTION}

Food security is the ability to access enough food for a healthy and active life. ${ }^{1}$ In the US, the risk of food insecurity varies by ethnicity, race, age, and socioeconomic status. ${ }^{1-3}$ For example, food insecurity is more prevalent in the following households: African American, Hispanic, those with children (especially young children), those with children and a single parent, and low-income. ${ }^{1}$ Despite record high participation in federal food assistance

\footnotetext{
${ }^{1}$ Department of Food Science and Human Nutrition, Colorado State University, Fort Collins, CO ${ }^{2}$ Department of Health Management and Informatics, University of Central Florida, Orlando, FL

Conflict of Interest Disclosure: The authors have not stated any conflicts of interest.

Address for correspondence: Christian King, PhD, Department of Health Management and Informatics, University of Central Florida, 4364 Scorpius St, HPA II Rm 203, Orlando, FL 32816-2205; Phone: (407) 823-4146; Fax: (407) 823-6138; E-mail: christian.king@ucf.edu (C) 2018 Society for Nutrition Education and Behavior. Published by Elsevier, Inc. All rights reserved.

https://doi.org/10.1016/j.jneb.2018.04.003
}

micronutrient deficiencies such as those in iron and zinc. ${ }^{7,8}$ These nutritional deficiencies have been found to lead to adverse development of the brain and its functioning in children. ${ }^{9-11}$ This can result in poor cognitive functioning (eg, practiced structural approaches) ${ }^{12}$ and physiological (eg, anemia, low energy, and stunted growth), ${ }^{2-4}$ behavioral (eg, self-control), ${ }^{13}$ and emotional (eg, interpersonal relations) problems in children. ${ }^{14,15}$ However, most of the empirical evidence on the negative consequences of food insecurity used cross-sectional data and there is more limited empirical evidence on the long-term negative outcomes resulting from food insecurity.

Most studies on the consequences of food insecurity focused on the average effect, which assumes that all children are similarly affected by food insecurity. However, evidence shows that the negative impacts of food insecurity on child cognitive outcomes and social skills are larger for girls, 
which suggests that children may be affected differently by food insecurity. ${ }^{16}$ These negative impacts of food insecurity could potentially be larger for demographic groups (such as more disadvantaged children) that are at higher risk for experiencing food insecurity. For example, food insecurity could have greater adverse impacts on brain development in more disadvantaged children, leading to poorer cognitive and behavioral outcomes. A greater understanding about how food insecurity affects children differently is necessary to respond adequately to the issue. This study used data from the Fragile Families and Child Wellbeing Study (FFCWS), a sample of children born to mostly low-income urban mothers, to examine associations between food insecurity and child cognitive outcomes and behavioral problems at different score percentiles using quantile regression. The FFCWS dataset is wellsuited for this because of its focus on disadvantaged families.

\section{METHODS}

\section{Participants}

The FFCWS, a longitudinal study, sampled about 5,000 couples and their children born between 1998 and 2000 in 20 large urban cities with a population > 200,000 in the US. By design, the study oversampled unmarried mothers because they are at higher risk for living in poverty and later facing potential separation from the father than are mothers from more traditional families. ${ }^{17}$ Review by the institutional review board was not required for this secondary analysis of the FFCWS dataset. ${ }^{18}$

Over the course of the study, both parents were interviewed at regular intervals. This study used data from the fourth wave of interviews (when the child was about age 5 years); the caregiver (usually the mother) also participated in an in-home survey that collected information on the child's cognitive and emotional development and overall health, the home environment, food insecurity, and the child's behaviors, among other data.

\section{Survey Instruments}

The FFCWS researchers measured children's cognitive outcomes using 2 instruments: the Peabody Picture Vocabulary Test-Revised, a measurement of children's receptive vocabulary capabilities for standard English and academic readiness ${ }^{19}$; and the Woodcock-Johnson Test of Achievement letter-word identification subtest, a measure of cognitive development. ${ }^{20}$

Children's behavioral outcomes were measured using the Child Behavior Checklist for Ages $1.5-5 .^{21}$ This checklist is a widely used instrument to assess children's behavioral and emotional (externalizing and internalizing) behaviors. For each item, mothers reported how often a specific behavior of the child was true $(0=$ not true, $1=$ sometimes true, and 2 = often or very true). Externalizing behaviors are directed toward others (eg, aggressive behaviors) and internalizing behaviors are negative emotions directed toward the self. ${ }^{22}$ The externalizing behaviors measure included 25 items (Cronbach $\alpha=.85$ ) and the internalizing behaviors measure included 17 items $(\alpha=.73)$. Examples of items included in the externalizing behavior scale were whether the child argued a lot, bullied, was disobedient, or destroyed things. Examples of items included in the internalizing behavior scale were whether the child worried, sulked a lot, was shy, or refused to talk. ${ }^{21}$ These cognitive outcomes and behavioral problems measures were standardized with a mean of 0 and SD of 1 to simplify the interpretation of associations.

Food insecurity was assessed at the household level using an 18-item scale instrument from the US Department of Agriculture. ${ }^{23}$ The survey asked questions by order of severity of food insecurity; households that responded affirmatively to $\geq 3$ items were classified as food insecure. ${ }^{23}$

\section{Control Variables}

Several control variables were included in this study that could potentially confound associations between food insecurity and child academic outcomes. Binary variables were constructed to indicate the mother's race/ethnicity (white, black, Hispanic, or other race), low birth weight, maternal education (less than high school, high school, some college, or college graduate and beyond), the mother's relationship with the father (married, cohabitating, nonresident, or separated), whether the mother had a new romantic partner, the mother's employment status (employed or not), whether the mother smoked during pregnancy, parental history of drug and alcohol abuse, whether the mother was an immigrant, and whether the mother received benefits from the Supplemental Nutrition Assistance Program at the time of the interview. Although the researchers controlled for the mother's race/ ethnicity and had information on the father's race/ethnicity, there was no direct information on the race/ ethnicity of the child. It is possible for some children that their race differed from the mother's and/or father's. Additional control variables included household income as a proportion of the federal poverty guidelines, mother's age when the child was born, the number of children in the home, whether the child was in poor or fair health, and whether the child had asthma.

A measure of maternal depression using the Composite Diagnostic Interview-Short Form was included. ${ }^{24}$ Mothers were considered to be depressed if they reported feeling depressed or unable to enjoy normally pleasurable activities and had $\geq 3$ of 7 additional symptoms, such as having trouble sleeping or feeling worthless. The analysis also controlled for social support, material hardship, parenting stress, and parents' relationship quality. For social support, mothers reported whether they could count on someone to: loan them \$200, loan them $\$ 1,000$, provide a temporary place to live, and help with emergency child care. The material hardship measure counted the number of financial hardships experienced by the mother, such as falling behind on rent or mortgage payments, or whether the electricity was turned off because of missed payments. ${ }^{25,26}$ Parenting stress was an average of 4 statements ranging from 1 to 4 (strongly disagree to strongly agree): (1) Being a parent is harder than I thought it would be, (2) I feel trapped by my responsibilities as a parent, (3) Taking care of my child is more work than pleasure, and (4) I often feel tired from raising a family. ${ }^{27,28}$ Parents' 
relationship quality was rated by mothers on a scale of 1 to 5 (poor to excellent). ${ }^{29,30}$

\section{Statistical Analyses}

The researchers used a difference of means $t$ test to test whether differences in the descriptive statistics were significant by gender (Table 1 ). Whereas previous studies used regression-based models to estimate the average association between food insecurity and child academic outcomes, this analysis used unconditional quantile regression. Quantile regression can model associations between independent and dependent variables at different points of the distribution of a continuous variable rather than just the mean. ${ }^{31}$ Quantile regression can be useful in identifying linear and nonlinear associations between cognitive and behavioral outcomes and food insecurity. In addition, it can be informative about the distribution of important risk factors that explain foodinsecure households. Using the FFCWS, which surveyed a majority of disadvantaged families, quantile regression can give useful insight into the multifaceted issue of food insecurity and its effects on young children. The quantile regressions estimated the associations between food insecurity and child academic outcomes at the 10th, 25 th, 50th, 75th, and 90th percentiles with robust SEs. The sample size included 2,046 children and their mothers for the behavioral outcomes and 1,684 children for the cognitive outcomes. Some variables with missing values were imputed using multiple imputation by chained equations to preserve these observations. ${ }^{32}$ Because the results were similar using the nonimputed data, only the results using imputation were reported. $P<.05$ was considered to indicate statistical significance. All analyses were conducted using Stata (version 14, StataCorp LP, College Station, TX).

\section{RESULTS}

\section{Participant Demographics}

Table 1 presents descriptive statistics for the sample by the child's gender. About $19 \%$ of children in this sample lived in food-insecure households. The characteristics reflect the oversampling of nonmarital births. For example, close to three quarters of mothers were African American or Hispanic, close to two thirds of mothers had at most a high school degree, and more than half of mothers were separated from the child's father. A $t$ test of differences of means showed that most of the differences in the average characteristics between boys and girls in this sample were statistically significant at $P<.05$. On average, girls had fewer behavior problems, scored higher on tests, and were less likely to be in poor health or to have asthma problems.

Table 2 presents estimates of the association between household food insecurity and externalizing behaviors, internalizing behaviors, Peabody vocabulary, and Woodcock-Johnson letter-word identification by percentile (10th, 25th, 50th, 75th, and 90th). Table 2 shows the fully adjusted models (unadjusted models not shown and available upon request), which included all of the control variables listed in Table 1. The coefficient reported for each quantile and outcome is that of food insecurity. They are $\beta$ values and are interpreted in the same way as in ordinary least squares regression. For externalizing and internalizing behaviors, children in the lowest percentiles had fewer behavior problems than did those in the highest percentiles. Household food insecurity was associated with more behavior problems (both externalizing and internalizing) and the negative association was largest for children with the most behavior problems (in the highest percentiles of behavior problems). For example, household food insecurity increased externalizing behavior problems by $0.32 \mathrm{SD}$ for children in the 90th percentile (high behavior problems) whereas it increased externalizing behavior problems by $0.02 \mathrm{SD}$ (not statistically significant) for children in the 10th percentile (low behavior problems).

\section{Cognitive and Behavioral Results}

For the Peabody Vocabulary test, household food insecurity was associated with lower scores only for children between the 50th and 90th percentiles. Household food insecurity did not have a statistically signifi- cant association for children with lower scores (10th and 25th percentiles). For the Woodcock-Johnson letter-word identification assessment, household food insecurity was associated with lower scores only for children in the 10th percentile. These estimates showed that the negative association between household food insecurity and child outcomes varied by percentile and outcome and was not uniform among students.

The same models were reestimated by gender (Table 3). For boys, household food insecurity was associated with externalizing behavior problems for those in the 50th and 75th percentiles. Food insecurity was associated with greater internalizing behavior problems in all percentiles. The association was more than twice as large for those in the 90th percentile than for those in the 10th and 25th percentiles. Food insecurity was associated with a lower Peabody vocabulary score only for those in the 75 th percentile. The association between food insecurity and Woodcock-Johnson letter-word identification scores was not statistically significant.

For girls, associations between food insecurity and child academic and behavioral outcomes followed a similar pattern as for boys. Food insecurity was associated with externalizing behavior problems and the association was larger for girls in the higher percentiles. Similarly, food insecurity was associated with internalizing behavior problems and the association was larger for the higher percentiles. On the other hand, food insecurity was associated with a lower Peabody vocabulary score only for girls in the 75th and 90th percentiles, which meant that it affected only girls with higher scores. There was no statistically significant association between food insecurity and Woodcock-Johnson letter-word identification scores by gender.

\section{DISCUSSION}

This study used quantile regression to examine how food insecurity affects child cognitive and behavioral outcomes at different points within the distribution; it also examined these associations by gender. The study found that food insecurity was associated 
Table 1. Descriptive Statistics of Fragile Families and Child Wellbeing Study Sample

\section{Variable}

Child outcomes

Externalizing behaviors

Internalizing behaviors

Peabody Picture Vocabulary Test

Woodcock-Johnson letter-word identification

Food-insecure household

Mother's race

White

Black

Hispanic

Other

Mother's education

Less than high school

High school degree

Some college

College graduate

Mother's relationship with father

\section{Married}

Cohabitating

Nonresident

Separated

Mother has a new romantic partner

Mother's relationship quality with father

Mother is an immigrant

Number of children

Mother is employed

Mother's age at birth of child, y

Household income to poverty ratio

Parental history of drug or alcohol abuse

Maternal smoking history during pregnancy

Low birth weight

Mother receives food stamp benefits

Mother is depressed

Social support

Material hardship

Parenting stress

Child is in poor health

Child has asthma problems

Sample size
Full sample (\% or Mean)

Boy (\% or Mean)

Girl (\% or Mean)

$\begin{array}{rrr}9.6 & 10.0 & 9.1^{\star *} \\ 4.3 & 4.4 & 4.3 \\ 86.2 & 85.0 & 87.5^{\star *} \\ 99.9 & 97.9 & 102.1^{\star *} \\ 19.2 & 19.7 & 18.6^{* *}\end{array}$

22.5

23.2

$21.7^{\text {* }}$

52.6

52.9

52.4

21.6

20.4

$22.9^{\text {** }}$

3.3

3.6

$3.0^{\text {** }}$

31.2

29.8

$32.7^{\text {** }}$

31.6

33.1

$29.9^{* *}$

26.0

25.4

$26.6^{* *}$

11.2

11.7

$10.7^{\text {** }}$

28.9

29.1

28.7

12.8

11.6

$14.0^{* *}$

3.7

2.8

$4.6^{\text {** }}$

54.6

56.5

$52.7^{\text {** }}$

28.6

30.1

$26.9^{\text {** }}$

3.3

3.3

3.2

10.5

10.3

10.7

2.6

59.3

25.2

2.6

2.6

58.2

$60.4^{\text {* }}$

25.1

$25.2^{*}$

1.9

1.9

1.9

23.7

24.0

$23.2^{*}$

20.2

18.7

$21.8^{\text {** }}$

10.0

45.2

9.0

$11.1^{\text {** }}$

46.0

$44.3^{\text {** }}$

17.1

17.6

$16.5^{\text {** }}$

3.2

3.2

$3.2^{*}$

1.1

1.1

1.1

2.2

2.2

$2.2^{\text {** }}$

11.3

13.6

$8.7^{\text {** }}$

8.2

10.6

$5.6^{\text {** }}$
977

${ }^{\star} P<.05 .{ }^{\star \star} P<.01$.

Note: $t$ tests for differences in means were used to test differences between gender characteristics. 
Table 2. Quantile Regressions of Associations Between Household Food Insecurity and Child Cognitive and Behavioral Outcomes

\section{Percentile score}

\begin{tabular}{|c|c|c|c|c|c|}
\hline Variable & 10th & 25th & 50th & 75th & 90th \\
\hline \multirow[t]{2}{*}{ Externalizing behaviors } & 0.02 & $0.24^{\star *}$ & $0.27^{\star *}$ & $0.28^{\star *}$ & $0.32^{\star *}$ \\
\hline & $(-0.05$ to 0.10$)$ & (0.12 to 0.36$)$ & $(0.15$ to 0.39$)$ & $(0.10$ to 0.46$)$ & (0.08 to 0.57 ) \\
\hline \multirow[t]{2}{*}{ Internalizing behaviors } & $0.28^{\star \star}$ & $0.25^{\star \star}$ & $0.39^{* \star}$ & $0.43^{\star \star}$ & $0.44^{\star \star}$ \\
\hline & (0.22 to 0.33$)$ & (0.15 to 0.35$)$ & (0.26 to 0.52$)$ & (0.26 to 0.61$)$ & (0.25 to 0.63 ) \\
\hline \multirow[t]{2}{*}{ Peabody Vocabulary } & -0.01 & -0.11 & $-0.16^{*}$ & $-0.19^{* \star}$ & $-0.14^{* *}$ \\
\hline & $(-0.20$ to 0.19$)$ & $(-0.26$ to 0.05$)$ & $(-0.29$ to -0.02$)$ & $(-0.33$ to -0.04$)$ & $(-0.24$ to -0.04$)$ \\
\hline \multirow[t]{2}{*}{ Woodcock-Johnson letter-word } & $-0.16^{*}$ & -0.01 & -0.07 & -0.03 & -0.03 \\
\hline & $(-0.30$ to -0.01$)$ & $(-0.16$ to 0.14$)$ & $(-0.18$ to 0.05$)$ & $(-0.16$ to 0.10$)$ & $(-0.08$ to 0.14$)$ \\
\hline
\end{tabular}

${ }^{*} P<.01 .{ }^{* *} P<.05$.

Note: The coefficient reported for each quantile and outcome is the coefficient of food insecurity. They are $\beta$ values and are interpreted the same way as in ordinary least squares regression. Each model for each percentile includes all control variables in Table 1. Confidence intervals are shown in parentheses and $t$ tests were performed for statistical significance.

Table 3. Quantile Regressions of Associations Between Household Food Insecurity and Child Cognitive and Behavioral Outcomes by Gender

\section{Percentile score}

\begin{tabular}{|c|c|c|c|c|c|}
\hline Variable & 10th & 25th & 50th & 75th & 90th \\
\hline \multicolumn{6}{|c|}{ Externalizing behaviors } \\
\hline \multirow[t]{2}{*}{ Boys } & 0.07 & 0.19 & $0.25^{\star \star}$ & $0.31^{*}$ & 0.22 \\
\hline & $(-0.03$ to 0.17$)$ & $(-0.02$ to 0.39$)$ & (0.09 to 0.42$)$ & (0.03 to 0.59$)$ & $(-0.00$ to 0.45$)$ \\
\hline \multirow[t]{2}{*}{ Girls } & 0.03 & $0.25^{\star \star}$ & $0.28^{\star *}$ & $0.29^{*}$ & $0.34^{\star \star}$ \\
\hline & $(-0.18$ to 0.25$)$ & (0.07 to 0.43$)$ & (0.10 to 0.46$)$ & (0.03 to 0.55$)$ & (0.08 to 0.60$)$ \\
\hline \multicolumn{6}{|c|}{ Internalizing behaviors } \\
\hline \multirow[t]{2}{*}{ Boys } & $0.23^{\star \star}$ & $0.21^{\star \star}$ & $0.29^{\star \star}$ & $0.31^{\star *}$ & $0.51^{\star \star}$ \\
\hline & (0.15 to 0.32$)$ & (0.11 to 0.31$)$ & 0.11 to 0.48$)$ & (0.10 to 0.51$)$ & (0.26 to 0.76$)$ \\
\hline \multirow[t]{2}{*}{ Girls } & $0.25^{\star \star}$ & $0.30^{\star \star}$ & $0.44^{\star \star}$ & $0.49^{\star *}$ & $0.39^{*}$ \\
\hline & (0.17 to 0.32$)$ & (0.13 to 0.46$)$ & (0.21 to 0.67$)$ & (0.28 to 0.70$)$ & (0.02 to 0.75$)$ \\
\hline \multicolumn{6}{|c|}{ Peabody Vocabulary } \\
\hline \multirow[t]{2}{*}{ Boys } & 0.07 & -0.16 & -0.14 & $-0.21^{\star}$ & -0.12 \\
\hline & $(-0.27$ to 0.42$)$ & $(-0.38$ to 0.07$)$ & $(-0.31$ to 0.03$)$ & $(-0.40$ to -0.042$)$ & $(-0.32$ to 0.08$)$ \\
\hline \multirow[t]{2}{*}{ Girls } & 0.11 & -0.01 & -0.11 & $-0.15^{\star}$ & $-0.19^{\star}$ \\
\hline & $(-0.09$ to 0.31$)$ & $(-0.19$ to 0.16$)$ & $(-0.26$ to 0.04$)$ & $(-0.30$ to -0.01$)$ & $(-0.36$ to -0.02$)$ \\
\hline \multicolumn{6}{|c|}{ Woodcock-Johnson letter-word } \\
\hline \multirow[t]{2}{*}{ Boys } & -0.11 & -0.01 & -0.12 & -0.05 & -0.05 \\
\hline & $(-0.40$ to 0.19$)$ & $(-0.22$ to 0.21$)$ & $(-0.28$ to 0.04$)$ & $(-0.22$ to 0.12$)$ & $(-0.31$ to 0.22$)$ \\
\hline \multirow[t]{2}{*}{ Girls } & -0.11 & -0.05 & 0.03 & 0.09 & 0.11 \\
\hline & $(-0.34$ to 0.12$)$ & $(-0.22$ to 0.13$)$ & $(-0.13$ to 0.20$)$ & $(-0.07$ to 0.25$)$ & $(-0.10$ to 0.31$)$ \\
\hline
\end{tabular}

${ }^{\star} P<.01 .{ }^{* *} P<.05$.

Note: The coefficient reported for each quantile and outcome is the coefficient of food insecurity. They are $\beta$ values and are interpreted the same way as in ordinary least squares regression. Each model for each percentile includes all control variables in Table 1. Confidence intervals are shown in parentheses. $t$ tests were performed for statistical significance. 
with externalizing and internalizing behavior problems in all quantiles. These findings were consistent with previous studies revealing that food insecurity has (on average) negative associations with child behavior problems $\mathrm{s}^{22}$ and with research showing that undernutrition and malnutrition have adverse impacts on brain development and functioning in children. $^{9-11}$ These associations remained statistically significant even after accounting for several potential confounding factors (eg, maternal depression, parenting stress, material hardship). For example, food insecurity increases the risk of maternal depression, and there is evidence that maternal depression mediates associations between household food insecurity and child behavior problems. $^{33,34}$

In addition, these associations were larger for children in the higher quantiles. This means that negative associations between food insecurity and behavior problems are larger for children who have greater behavior problems to begin with. These findings suggest that undernutrition and malnutrition may have greater adverse impacts on some children, which may lead to greater behavioral problems. Because child behavior problems have negative consequences such as lower educational attainment and a greater risk for delinquency, ${ }^{35-37}$ food insecurity may exacerbate these negative consequences and social disparities among children.

For the cognitive outcomes, food insecurity was associated with a lower Peabody vocabulary score for children in the 50th, 75 th, and 90th percentiles. Therefore, food insecurity negatively affected only children in the upper half of the test score distribution. This contrasted with findings on the behavioral outcomes. Also, food insecurity was associated with lower Woodcock-Johnson letter-word identification scores only for children in the 10th percentile, which was consistent with the behavioral outcomes, because children with behavior problems are likely to have lower test scores. $^{38,39}$

The patterns in these associations were similar when they were examined by gender. Household food insecurity was associated with greater externalizing and internalizing behavior problems for both boys and girls, and the association was larger for children in the higher percentiles or those with greater behavior problems. For cognitive outcomes, food insecurity was associated with a lower Peabody vocabulary score only for boys and girls in the higher percentiles (75th and 90th). On the other hand, the association between food insecurity and Woodcock-Johnson letter-word identification score was not statistically significant for either boys or girls.

The study had some limitations. First, the findings are generalizable only to children of unmarried mothers, who are aged 5 years and living in large urban cities. Nevertheless, this demographic population is substantially at larger risk for experiencing food insecurity, living in poverty, and having an unstable family structure. Second, the study used a binary measure of food insecurity that includes lowfood secure and very low-food secure households. Very low food security is a much more severe form of food insecurity and households were considered very low food secure if they responded affirmatively to $\geq 8$ of the 18-question module. ${ }^{23}$ The sample in this study had only 89 children (about $4 \%)$ living in very low-food secure households, which may not have provided enough statistical power to examine very low food security. Another limitation relates to the years in which the data were collected (between 2003 and 2006), which may not reflect current trends and situations. Finally, although the study controlled for several potential confounding factors, there might have been additional unmeasured characteristics that may explain these associations.

Findings suggest that the negative associations between food insecurity and behavioral outcomes are larger for children with greater behavior problems to begin with. On the other hand, for cognitive outcomes, the negative associations with food insecurity are statistically significant only for the $\geq 50$ th percentiles for the Peabody vocabulary score. There is mixed evidence of an association with the WoodcockJohnson letter-word identification test. The analyses by gender showed a similar pattern. The current findings contribute to a greater understanding of the relationship between household food insecurity and child cognitive and behavioral outcomes and suggest that food insecurity may potentially exacerbate some of the negative consequences of child behavior problems for educational attainment.

\section{IMPLICATIONS FOR RESEARCH AND PRACTICE}

This research used quantile regression to show that the size of the negative associations between food insecurity and child academic and behavioral outcomes differed at different points in the distribution. For the behavioral outcomes, the negative associations with food insecurity were larger for children with greater behavioral problems to begin with. Study findings highlighted the importance of screening children with behavioral problems and poor cognitive outcomes because they may be a greater risk for experiencing food insecurity. These results support the importance of increasing mindfulness about possible food insecurity among students and suggest that behavioral problems and poor cognitive outcomes should be approached holistically with possible food insecurity in mind. This study also provides a snapshot of the possible interactions that food insecurity might have with behavioral and cognitive outcomes, and it may be useful to those who work with children when trying to identify household food insecurity.

The School Breakfast Program (SBP) and National School Lunch Program (NSLP) are 2 school-based nutrition assistance programs that have been found to be effective in reducing food insecurity. ${ }^{40,41}$ However, takeup rates for the SBP have been found to be lower than for the NSLP because of the difficulty some children face in coming to school before the start of classes to have breakfast. To remove this impracticality, some schools have provided breakfast in the classroom, which has been found to increase the participation rate in the SBP substantially. ${ }^{42}$ Another potential way to increase the participation rate in the SBP and NSLP is through the Community Eligibility Provision, which 
allows schools with high poverty rates to serve free meals at no cost to all enrolled students. ${ }^{43}$ These potential policy options could improve behavioral and cognitive outcomes, reduce absenteeism, and improve educational attainment in children, especially those who are most vulnerable. In addition, the Supplemental Nutrition Assistance Program has been found to be effective in reducing food insecurity and poverty. ${ }^{44}$ More research is needed to understand the long-term negative impacts of food insecurity on child academic and behavioral outcomes at different points of the distribution. In addition, future research is needed to examine whether the mechanisms through which food insecurity affects children negatively differ at various points of the distribution.

\section{REFERENCES}

1. Coleman-Jensen A, Rabbitt MP, Nord M, Singh A. Household food security in the United States in. US Department of Agriculture: Economic Research Service. 2016. https://www.ers.usda.gov/ webdocs/publications/84973/err237.pdf. Accessed November 15, 2017.

2. Gundersen C, Kreider B. Bounding the effects of food insecurity on children's health outcomes. J Health Econ. 2009; 28:971-983.

3. Alaimo K, Briefel RR, Frongillo E, Olson CM. Food insufficiency exists in the United States: results from the third National Health and Nutrition Examination Survey (NHANES III). Am J Public Health. 1998;88:419-426.

4. Cook JT, Frank DA, Berkowitz C, et al. Food insecurity is associated with adverse health outcomes among human infants and toddlers. J Nutr. 2004;134:14321438.

5. Kirkpatrick SI, McIntyre L, Potestio ML. Child hunger and long-term adverse consequences for health. Arch Pediatr Adolesc Med. 2010;164:754-762.

6. Ryu JH, Bartfeld JS. Household food insecurity during childhood and subsequent health status: the early childhood longitudinal study-kindergarten cohort. Am J Public Health. 2012;102:e50-e55.

7. Kirkpatrick SI, Tarasuk V. Food insecurity is associated with nutrient inadequacies among Canadian adults and adolescents. J Nutr. 2008;138:604-612.
8. Skalicky A, Meyers AF, Adams WG, Yang Z, Cook JT, Frank DA. Child food insecurity and iron deficiency anemia in low-income infants and toddlers in the United States. Matern Child Health J. 2006;10:177.

9. Benton D. Micronutrient status, cognition and behavioral problems in childhood. Eur J Nutr. 2008;47:3850 .

10. Georgieff MK. Nutrition and the developing brain: nutrient priorities and measurement. Am J Clin Nutr. 2007;85: 614S-620S.

11. Knickmeyer RC, Gouttard S, Kang C, et al. A structural MRI study of human brain development from birth to 2 years. J Neurosci. 2008;28:12176-12182.

12. Gundersen C, Ziliak JP. Food insecurity and health outcomes. Health Aff. 2015;34:1830-1839.

13. Kleinman RE, Murphy JM, Little M, et al. Hunger in children in the United States: potential behavioral and emotional correlates. Pediatrics. 1998;101: e3.

14. Grantham-McGregor S, Ani C. A review of studies on the effect of iron deficiency on cognitive development in children. J Nutr. 2001;131:649S-668S.

15. Slopen N, Fitzmaurice G, Williams DR, Gilman SE. Poverty, food insecurity, and the behavior for childhood internalizing and externalizing disorders. $J$ Am Acad Child Adolesc Psychiatr. 2010;49:444452.

16. Jyoti DF, Frongillo EA, Jones SJ. Food insecurity affects school children's academic performance, weight gain, and social skills. J Nutr. 2005;135:28312839.

17. Reichman NE, Teitler JO, Garfinkel I, McLanahan SS. Fragile families: sample and design. Child Youth Serv Rev. 2001; 23:303-326.

18. Code of Federal Regulations. Title 45, Public Welfare, Department of Health and Human Services, Part 46, Protection of Human Subjects. 45 CFR 46.101 (b) (4).

19. Dunn LM, Dunn LM. Examiner's Manual for the PPVT-III Peabody Picture Vocabulary Test: Form IIIA and Form IIIB. Pines, MN: American Guidance Service; 1997.

20. Woodcock RW, McGrew KS, Mather N. Woodcock-Johnson Tests of Achievement. Itasca, IL: Riverside Publishing; 2001.

21. Achenbach TM. Manual for the Child Behavior Checklist/4-18 and 991 Profile. Burlington, VT: Department of Psychiatry, University of Vermont; 1991
22. Eisenberg N, Cumberland A, Spinrad TL, et al. The relations of regulation and emotionality to children's externalizing and internalizing problem behavior. Child Dev. 2001;72:1112-1134.

23. US Department of Agriculture. U.S. Household Food Security Survey Module: Three-Stage Design, With Screeners. Economic Research Service, US Dept of Agriculture. 2012. https://www.ers .usda.gov/media/8271/hh2012.pdf. Accessed November 15, 2017.

24. Kessler RC, Andrews G, Mroczek D, Ustun B, Wittchen HU. The World Health Organization composite international diagnostic interview shortform (CIDI-SF). Int J Methods Psychiatr Res. 1998;7:171-185.

25. Zilanawala A, Pilkauskas NV. Material hardship and child socioemotional behaviors: differences by types of hardship, timing, and duration. Child Youth Serv Rev. 2012;34:814-825.

26. King C. Food insecurity and child behavior problems in fragile families. Econ Hum Biol. 2018;28:14-22.

27. Nomaguchi K, Johnson W. Parenting stress among low-income and workingclass fathers: the role of employment. $J$ Fam Issues. 2016;37:1535-1557.

28. Pilarz AR, Hill HD. Child-care instability and behavior problems: does parenting stress mediate the relationship? J Marriage Fam. 2017;79:13531368.

29. McClain L, Brown SL. The roles of fathers' involvement and coparenting in relationship quality among cohabiting and married parents. Sex Roles. 2017;76:334345.

30. Turney K. Hopelessly devoted? Relationship quality during and after incarceration. J Marriage Fam. 2015;77: 480-495.

31. Koenker R, Hallock KF. Quantile regression. J Econ Perspect. 2001;15:143156.

32. Royston P. Multiple imputation of missing values: further update of ice, with an emphasis on categorical variables. Stata J. 2009;9:466-477.

33. Whitaker RC, Phillips SM, Orzol SM. Food insecurity and the risks of depression and anxiety in mothers and behavior problems in their preschool-aged children. Pediatrics. 2006;118:e859-e868.

34. Melchior M, Caspi A, Howard LM, et al. Mental health context of food insecurity: a representative cohort of families with young children. Pediatrics. 2009;124: e564-e572. 


\section{Hobbs and King}

35. McLeod JD, Kaiser K. Childhood emotional and behavioral problems and educational attainment. Am Sociol Rev. 2004;69:636-658.

36. Nagin D, Tremblay RE. Trajectories of boys' physical aggression, opposition, and hyperactivity on the path to physically violent and nonviolent juvenile delinquency. Child Dev. 1999;70: 1181-1196.

37. Webster-Stratton C, Taylor T. Nipping early risk factors in the bud: preventing substance abuse, delinquency, and violence in adolescence through interventions targeted at young children (0-8 years). Prev Sci. 2001;2:165192.

- Volume 50, Number 7, 2018

38. Hinshaw SP. Externalizing behavior problems and academic underachievement in childhood and adolescence: causal relationships and underlying mechanisms. Psychol Bull. 1992;111:127-155.

39. Loe IM, Feldman HM. Academic and educational outcomes of children with ADHD. J Pediatr Psychol. 2007;32:643654.

40. Bartfeld JS, Ahn HM. The School Breakfast Program strengthens household food security among low-income households with elementary school children. J Nutr. 2011;141:470-475.

41. Gundersen C, Kreider B, Pepper J. The impact of the National School Lunch Program on child health: a nonparamet- ric bounds analysis. J Econom. 2012;166: 79-91.

42. Corcoran SP, Elbel B, Schwartz AE. The effect of breakfast in the classroom on obesity and academic performance: evidence from New York City. J Policy Anal Manag. 2016;35:509-532.

43. US Department of Agriculture. Food and Nutrition Service. Community Eligibility Provision Resource Center. 2018. https://www.fns.usda.gov/school-meals/ community-eligibility-provision-resource -center. Accessed February 15, 2018.

44. Bartfeld J, Gundersen C, Smeeding T, Ziliak JP. SNAP Matters: How Food Stamps Affect Health and Well-Being. Palo Alto, CA: Stanford University Press; 2015.

\section{JNEB's 2018 Best GEM Award}

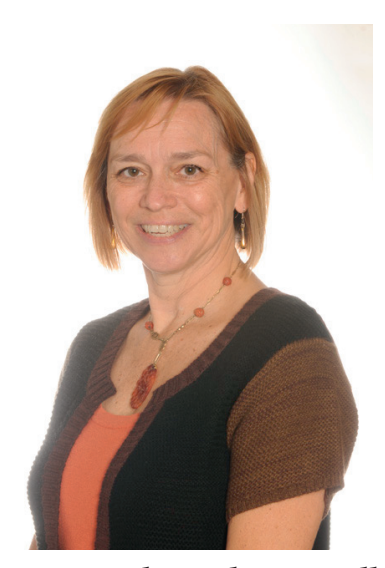

Leanne Whiteside-Mansell
Leanne Whiteside-Mansell and Taren Swindle

are the recipients of the JNEB Best GEM Award for their article

GEM No. 570: Together We Inspire Smart Eating: A Preschool Curriculum for Obesity Prevention in Low-Income Families J Nutr Educ Behav. 2017; 49:789-792

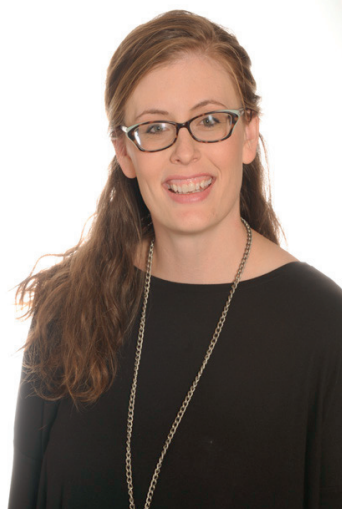

Taren Swindle 